\title{
Sharing biodiversity data: citizen scientists' concerns and motivations
}

\author{
Wessel Ganzevoort ${ }^{1}$ (D) Riyan J. G. van den Born ${ }^{1}$ • \\ Willem Halffman ${ }^{1} \cdot$ Sander Turnhout $^{2}$
}

Received: 26 December 2016/Revised: 6 June 2017/Accepted: 12 June 2017/

Published online: 16 June 2017

(C) The Author(s) 2017. This article is an open access publication

\begin{abstract}
Citizen scientists play a pivotal role in providing necessary biodiversity data. To ensure the continued involvement of a strong volunteer base, insight into the concerns and motivations of voluntary recorders is crucial. This paper presents the findings of a largescale survey $(N=2193)$ among Dutch volunteer biodiversity recorders of diverse taxa, and focuses on three questions: what are the characteristics of these citizen scientists regarding their activities and socio-demographic background, what are their motivations for recording biodiversity, and what are their views on data sharing and ownership? Our findings show that a connection to, interest in and concern for nature are the most important motivations for biodiversity recorders. Volunteer recorders have high expectations regarding the impact of their data, both for their own learning as well as for science and management. Almost half the volunteers consider their data to be public goods, but this does not mean they support unconditional data sharing. Instead, the acceptability of data sharing with third parties seems strongly linked to the goals of the user. We discuss the implications of our findings for practitioners, such as the role of biology curricula and the importance of learning opportunities to redress the lack of younger volunteers. We argue that conceptualising volunteer recorders as data custodians rather than owners helps to
\end{abstract}

Communicated by Peter Bridgewater.

This article belongs to the Topical Collection: Biodiversity appreciation and engagement.

Electronic supplementary material The online version of this article (doi:10.1007/s10531-017-1391-z) contains supplementary material, which is available to authorized users.

Wessel Ganzevoort

w.ganzevoort@fnwi.ru.nl

1 Institute for Science, Innovation and Society, Radboud University, P.O. Box 9010, 6500 GL Nijmegen, The Netherlands

2 SoortenNL, P.O. Box 9010, 6500 GL Nijmegen, The Netherlands 
understand their perspective on data sharing, and emphasize the importance of clear and transparent data policy that respects volunteers' views on their data.

Keywords Biodiversity monitoring · Citizen science $\cdot$ Public participation in scientific research $\cdot$ Open data $\cdot$ Data sharing $\cdot$ Volunteer motivations

\section{Introduction: a different perspective on citizen scientists}

Citizen science is on the rise. More and more research projects involve volunteers who collect biodiversity data, interpret astronomic images, fold proteins, or even help solve mathematical problems (Conrad and Hilchey 2011; Dickinson et al. 2010; Franzoni and Sauermann 2014; Kullenberg and Kasperowski 2016). Scientists are discovering the enormous potential of non-professional citizen scientists, mobilizing their volunteer commitment to undertake research projects that would otherwise be unachievable or unaffordable. In the wake of such endeavours, there is a modest but growing body of social scientific research studying this phenomenon of citizen science. These studies report and discuss experiences with citizen science projects, analyse tensions and limitations, and provide management recommendations (e.g., Bone et al. 2012; Newman et al. 2003; Van Vliet et al. 2014; Whitelaw et al. 2003).

Biodiversity researchers too have been debating the potential of citizen science, especially in the form of volunteer biodiversity recorders who produce atlases, periodic surveys, or targeted monitoring projects, sometimes combined with conservation efforts (Catlin-Groves 2012). There is an ongoing debate in the literature on whether citizen science as a method provides data of sufficient quality to merit the costs (Schmeller et al. 2008), or whether investments in citizen science yield sufficient numbers of research papers and citations to be cost-effective (Tulloch et al. 2013).

Compelled by both urgent conservation problems and the publication pressure typical of current research careers, it might seem logical for biodiversity researchers to weigh the advantages of citizen science in the cold logic of a potential resource. Hence we find phrases such as citizen scientists representing "a free source of labour, skills, computational power and even finance" (Silvertown 2009, p. 467), or how much "bang for your buck" in terms of scientific outputs" different types of citizen science projects provide (Tulloch et al. 2013, p. 135).

However, involving volunteers is much more complex than such an instrumental view may suggest. Social scientists studying biodiversity recorders have signalled that this portrayal as 'research instruments' can be a potential source of conflict. These volunteers object to being cast as what Ellis and Waterton (2004) refer to as "automated data-drones" (p. 98)-just like most scientists would not want to be considered publication-producing 'research drones'. Volunteers have their own ideas about what constitutes appropriate and respectful use of their data, and might decline to share them if their trust is breached (Lawrence and Turnhout 2010); they are clearly not the docile data collectors they are sometimes made out to be (Resnik et al. 2015).

This observation raises important questions, such as how biodiversity recorders feel about the data they collect, and what motivates them to collect and share these data. Maintaining the engagement and enthusiasm of volunteer recorders around the world is crucial: not only do national and international initiatives like the Global Biodiversity 
Information Facility (GBIF) fuel a demand for biodiversity data, but (as noted in the next section) involvement of volunteers in biodiversity-related citizen science is linked to a diverse range of benefits for participants. These may include cognitive and experiential learning outcomes and a strengthened connection with nature (Groulx et al. 2017) and mental and physiological health benefits associated with nature engagement (Russell et al. 2013). Biodiversity-related citizen science may thus not only contribute to biodiversity conservation through direct provision of data, but also indirectly through strengthening participants' awareness of and connection with biodiversity and the natural world.

Using the Dutch national biodiversity recorder as an example, our aim is to gain insight into the interrelated factors of volunteer biodiversity recorders' background, motivations, and views on sharing data, in order to learn more about what drives citizen scientists to record biodiversity, and to assist practitioners in connecting with their volunteers' concerns and motivations.

\section{Who is the citizen scientist?}

Citizen science is a broad form of cooperation between professional scientists and the public (Bonney et al. 2016), which is in theory open to anyone willing to participate. However, experience has shown that different segments of the population are more prone to participate than others (Soleri et al. 2016). Both Hobbs and White (2012) and Pandya (2012) note that citizen scientists currently tend to be whiter, older and more middle-class than broader society; a similar pattern is found in volunteering in general (Measham and Barnett 2008). For instance, in their study of the Second Southern African Bird Atlas Project, Wright et al. (2015, pp. 1017-1018) found that volunteers in both their sample and the entire programme were overwhelmingly older white males with high levels of education and income. In addition, in a survey among potential marine citizen scientists, Martin et al. (2016) found that interest in participation was positively correlated with both education in science and previous participation in scientific research. This indicates that this will continue to influence future volunteer recruitment, and will not likely resolve itself without purposeful effort.

This is a missed opportunity, as participation is presumed to lead to several benefits for the citizen scientist, such as increased understanding and appreciation of science (Brossard et al. 2005; Cronje et al. 2011; Trumbull et al. 2000), stronger bonds with nature (Ellis and Waterton 2005; Lawrence 2006) and social bonding (Bell et al. 2008). In addition, citizen science as an experience in nature could raise an interest in and support for nature conservation, especially at a younger age; Brewer (2006) notes that "many conservation biologists reminisce about having their interest kindled through early experiences in nature in the company of friends and mentors" (p. 691). In order to extend these potential benefits to a more diverse public, insight into the profile and motivations of the volunteer base is important.

\section{Citizen scientists' motivations}

If scientists are to see citizen scientists as colleagues rather than 'data-drones', they must gain an understanding of volunteers' motivations for participating. Meeting the expectations of volunteers and engaging their knowledge and expertise helps to maintain their motivation to contribute and prevents "poor recruitment or high exit rates from research programs" (Wright et al. 2015, p. 1015). 
Several authors have found that connecting with and learning about local nature and biodiversity is a key motivation for participation in nature volunteering (e.g., Hobbs and White 2012). For instance, Guiney and Oberhauser (2010) found that their conservation volunteers gave higher scores to nature-related motivations than to social or career-related motivations (p. 189), and Bruyere and Rappe (2007) found that to 'help the environment' was by far the highest-scoring motivation in their factor analysis of environmental volunteer motivations (p. 509). Lawrence (2006) even suggests that biodiversity recording can function as an excuse for spending quality time outdoors and "indulging in nature, or fleeing from family and social demands" (p. 292). As noted by Bell et al. (2008), learning about nature through citizen science is an important aspect of this bonding with nature:

[V]olunteers narrated to us their enjoyment in being outdoors and feeling close to nature, but such pleasures are neither exclusive nor specific to volunteer monitoring. Rather, the particular intimacy with the natural world developed through such activities is closely associated with a growing understanding of how the natural world works (p. 3450).

In addition to learning about and connecting with nature and biodiversity in general, some authors have called attention to the importance of specific places in motivating nature-based citizen science. Lawrence (2009) notes that citizen science data often arise out, and are given personal meaning through, long-term interaction with a specific place. In addition, Haywood $(2014,2016)$ has drawn attention to the importance of sense of place, i.e. the meaning of and attachment to specific sites, as both a possible motivation for and result of participation in citizen science. Specifically, Haywood et al. (2016) found that knowledge and familiarity developed through repeated sampling visits was connected to stronger attachment to place, such as a sense of ownership.

Bonding with like-minded people can also play an important role in nature volunteering. Asah and Blahna (2013) showed that social and community motivations were crucial for the commitment of urban conservation volunteers. Another possible motivation is a sense of personal achievement and pride in biodiversity recording (Lawrence and Turnhout 2010, p. 356). In addition, participation can be inspired by the desire to contribute to conservation science or management. With the literature discussing many examples of the contribution of citizen science to research and management (Dickinson et al. 2010; Lovell et al. 2009; Shirk et al. 2012), many authors also stress the importance of communicating with volunteers about the impact of their work, as the awareness of making a concrete contribution is an important motivator for investing time and effort (e.g., Bonney et al. 2009; Gouveia et al. 2004).

\section{Data sharing in citizen science}

Access to and sharing of citizen science data is of crucial importance: open data and data sharing with both project participants and outside parties can improve the data's relevance and trustworthiness for science, policy and management (Freitag et al. 2016; Soranno et al. 2015). Several practical issues regarding data sharing and use are debated in the literature, especially how to organise, validate, integrate and analyse this data (Gouveia et al. 2004; Newman et al. 2012; Resnik et al. 2015). Citizen science still deals with a (perceived) "image problem" regarding data quality (Riesch and Potter 2014, p. 113), though steps can be taken to assuage this concern (e.g., Bone et al. 2012; Sullivan et al. 2014; Theobald et al. 2015). Other practical issues in data sharing include legal questions (e.g., who owns database records), concerns about the disturbance of rare species, and volunteer privacy 
(Newman et al. 2012), the latter two being especially relevant when data are georeferenced.

However, sociology of science cautions us regarding a more fundamental concern related to the difference between data and knowledge. In order for records to be 'usable' as biodiversity data, they must be submitted in a structured and standardised format, objectively validated, and then transmitted to and stored in databases (Turnhout and BoonmanBerson 2011). However, Ellis and Waterton (2005, p. 688) note that tensions may arise when volunteer data become "disembedded from their original source and the humannature contractual relationships which are implied in their production". The standardisation and decontextualisation implicit in centralised biodiversity databases provides opportunities for conservation, yet we must be wary of the contextual richness we lose in the process and the effects this has on both data utilisation and volunteer motivation (Turnhout and Boonman-Berson 2011; Turnhout et al. 2016). This requires project managers to consider the views of citizen scientists regarding ownership and appropriate use of their data.

\section{The aims of this study}

Since volunteer or enthusiast natural history research is actually older than its professionalised counterpart (Bois et al. 2011; Miller-Rushing et al. 2012), we argue that cooperation between biodiversity researchers and citizen scientists is a more productive perspective than researchers making use of volunteers. Cooperation may cover the entire spectrum between relatively passive data collection and independent research by citizens (Haklay 2013; Shirk et al. 2012), but leaves more room for collegial approaches where the views, knowledge and skills of both professional and citizen scientists are mutually acknowledged.

This conception of citizen science implies that both scholars and policymakers in the field of biodiversity conservation will benefit from a better understanding of the citizen scientists themselves. Cooperation requires a thorough understanding of their background, motivations and goals. Understanding why citizen scientists make the commitment they do, and ensuring responsiveness to their concerns and motivations, is necessary if we are to take their engagement seriously (Land-Zandstra et al. 2016). This includes citizen scientists' views on data sharing, which are rarely studied empirically. Lawrence and Turnhout (2010) note that while contributing to science is an important motivation for volunteer biodiversity recorders, they also value the context of their sightings and need to trust that their data will be used respectfully and for the right purposes, "not ... simply as a commodity that can be bought and sold" (p. 359).

In order to reach new audiences or increase engagement of existing volunteers, scholars and practitioners can use methods such as surveys and interviews to gain a deeper understanding of a project's participants. For instance, using a combination of surveys, focus groups and interviews, Merenlender et al. (2016) found an overrepresentation of older and wealthier participants in California and Virginia Naturalist programmes, and used their findings to enact changes to engage a more diverse audience, e.g., through providing scholarships and course credit. Regarding existing participants, Haywood (2016) notes that programme evaluation is often done from the perspective of scientists rather than volunteers. Based on interviews and focus groups, he recommended several ways to improve engagement, e.g., by fostering social networking among volunteers, asking volunteers to recommend new variables to monitor, or allowing motivated individuals to take up more complex tasks. 
This section has illustrated the importance for scholars and practitioners to understand their citizen scientist colleagues in order to stimulate engagement, diversify the volunteer base, and establish a cooperative base to improve the project itself. To gain insight into these matters and assist practitioners in biodiversity-oriented citizen science, we present the results of a large-scale survey $(N=2193)$ among Dutch volunteers recording diverse taxa, and explore three main research questions:

1. What are the characteristics of these citizen scientists regarding their activities and socio-demographic background?

2. What are their motivations for monitoring biodiversity?

3. What are their views on data sharing and ownership?

\section{Materials and methods}

A questionnaire was designed in the online survey platform LimeSurvey (www. limesurvey.org) to gain insight into the background, motivations and views on data sharing of volunteer biodiversity recorders, specifically those that submit their data to an online portal. To ensure the relevance of the results to practitioners in the field of biodiversity conservation, the questionnaire was designed in close cooperation with representatives of NLBIF, the funder of the research, as well as many Dutch nature organisations and biodiversity monitoring platforms. ${ }^{1}$ The final questionnaire was also piloted among a few of their representatives and several scientists not involved in the project.

The survey covered four topics: the activities of the volunteers (e.g., submitted taxa and frequency of submission, years active, locations), their motivations (including their validation and learning strategies and their views on the significance of their efforts), their views on data sharing (e.g., data ownership, acceptable use and conditions on sharing) and socio-demographic questions (age, gender, education, sectoral employment and postcode). The questionnaire, including the response scales or options for each question, can be found in Online Resource 1. Most questions were either multiple-choice (e.g., "what do you do when you doubt a sighting?") or took the form of a group of items or statements with a response scale. The full questionnaire contained a total of 35 questions, with an estimated completion time of around $15 \mathrm{~min}$.

Regarding motivations for biodiversity recording, respondents were given a list of 12 motivations (ordered randomly for each respondent) based on our literature review reported above and the EU FP7 project BIOMOT, an empirical study into the motivations of committed actors for nature (Admiraal et al. 2017). Respondents were asked to arrange these motivations in descending order of importance and were free to leave out any motivations deemed unimportant. Although this method may force respondents to create an imposed hierarchy among motivations considered equally important, it avoids the more serious problem of careless equivalent scoring on a response scale (i.e., the problem of straight-lining, see Maronick 2009).

\footnotetext{
1 The organisations that commented on the draft survey are Waarneming.nl; The Dutch National Database Flora and Fauna (NDFF); Nature's Calendar (part of Nature Today); Sovon Dutch Centre for Field Ornithology; Reptile, Amphibian \& Fish Conservation Netherlands (RAVON); Dutch Foundation for Botanical Research (FLORON); European Invertebrate Survey (EIS); Dutch Butterfly Conservation; The Dutch Mammal Society; and Naturalis Biodiversity Center.
} 
Since our goal was to reach a specific population that is diffused and difficult-to-reach (Dutch volunteer biodiversity recorders who submit data), we employed purposive sampling to reach as many respondents as possible fitting these criteria, using a variety of channels (Neuman 2014). The online survey was active for a month (September-October 2015). The organisations consulted in the survey design (see footnote 1) distributed the survey link throughout their volunteer networks using a mixture of direct emails to volunteers, online newsletters, and social media posts. Our sampling approach involved an initial introductory brief with the link to the survey, and two reminders sent to all organisations over the next few weeks. The involvement of these diverse organisations ensured both a significant number of respondents as well as a wide geographical scope and breadth of taxonomical focus, though the chosen sampling method limits the representativeness of the sample (see "Reflections on generalizability"). The final sample consisted of 2193 completed questionnaires, a completion rate of $66.7 \%$. Respondents were spread throughout the country (Online Resource 2).

Data were analysed in SPSS version 21. Aside from descriptive statistics, we used Pearson's Chi squared tests to analyse associations between categorical variables, MannWhitney tests to compare means, and Spearman's rank correlation coefficient for checking bivariate correlations between ordinal and/or discrete variables (Field 2013). Non-parametric tests were chosen because normality tests (Kolmogorov-Smirnov and ShapiroWilk) indicated significant deviations from the normal distribution. In all cases $p<0.05$ was taken as a minimum value for statistical significance. To allow Pearson's Chi squared tests to include age or years active as volunteer recorder, we recoded these continuous variables into categories $(<35,35-49,50-64$, and $65+$ for age; $<2,2-5,6-10,11-15$, and $16+$ for years active).

The motivation ranking scale was analysed by scoring each motivation based on the rank given to it by each respondent (e.g., 12 points for 1 st rank, 11 points for 2 nd rank, all the way to 1 point for 12 th rank, with 0 points given if the motivation was not included at all) and then summating these scores across all respondents to arrive at a final score for that motivation. This allowed us to create a final ranking of the 12 motivations. Scores were not weighted based on how many motivations respondents had included in their personal ranking. To compare relative popularity of motivations across demographic categories using Pearson's Chi squared tests, we created binary variables for each motivation based on whether a respondent had included that motivation in their top three motivations.

\section{Results}

\section{Volunteer profile}

Table 1 summarises the socio-demographic profile of our sample. Regarding age, it is notable that the age groups 80+, 0-19 and 20-39 are underrepresented among the volunteer recorders compared to the general population, while those between 40 and 79 years old are overrepresented. Table 1 also shows that the Dutch volunteer naturalists in our sample are overwhelmingly male and much more highly educated than the general population. Volunteers have been volunteer recorders for an average of 10.4 years; a MannWhitney test showed that the average years active was significantly higher for male $(M=11.3, S D=10.7)$ than for female $(M=7.6, S D=8.3)$ respondents $(\mathrm{U}=330.73$, $p<0.001)$. This was not related to male respondents being older than females, as mean 
Table 1 Socio-demographics. Dutch general population data based on census data from CBS (Statistics Netherlands) for 2016 (age and gender; CBS 2017a) and 2014 (higher education; CBS 2017b)

\begin{tabular}{lll}
\hline & Sample & Dutch population \\
\hline Age $^{\mathrm{a}}$ & & \\
Mean $(S D)$ & $53.7(13.6)$ & $41.5(-)$ \\
$0-19$ & $1.1 \%$ & $22.5 \%$ \\
$20-39$ & $15.0 \%$ & $24.5 \%$ \\
$40-64$ & $60.5 \%$ & $34.8 \%$ \\
$65-79$ & $22.7 \%$ & $13.8 \%$ \\
$80+$ & $0.6 \%$ & $4.4 \%$ \\
Gender & & $49.6 \%$ \\
Male & $75.4 \%$ & $50.4 \%$ \\
Female & $24.6 \%$ & $29.4 \%$ \\
Higher education completed & $61.7 \%$ & - \\
Mean years active $(S D)$ & $10.4(10.3)$ & - \\
Paid position in nature/environment sector & $18.2 \%$ & \\
\hline
\end{tabular}

${ }^{\mathrm{a}} n=2175$

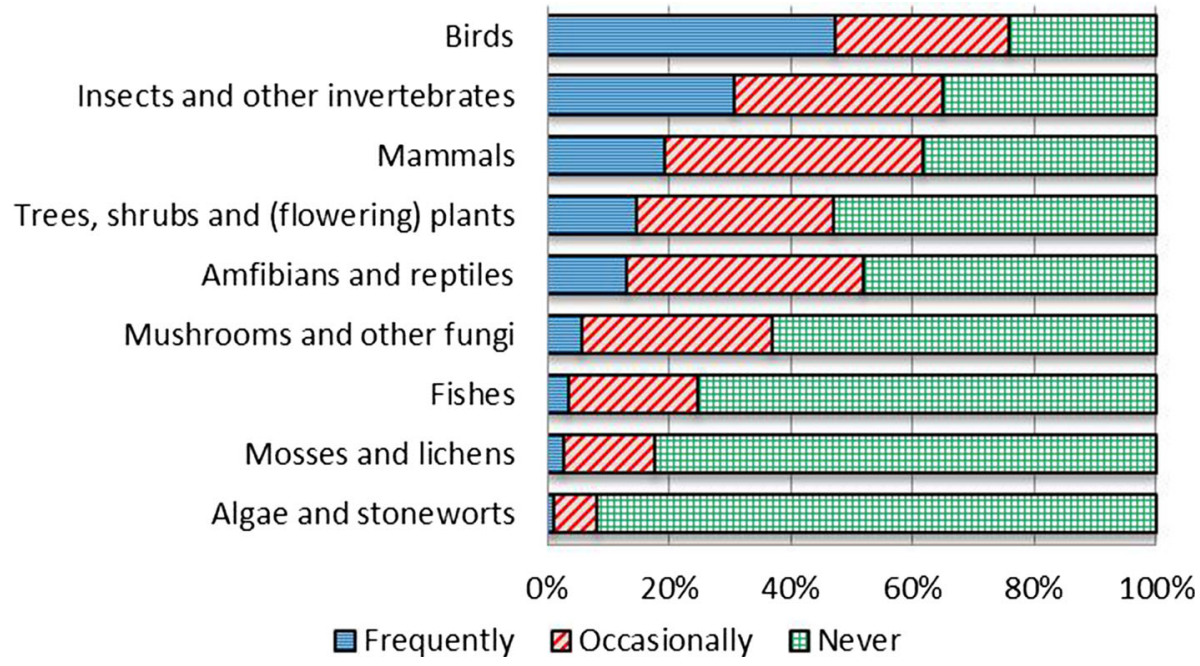

Fig. 1 Self-reported frequency of submission per taxa $(n=1923)$, respondents could pick multiple taxa. Frequently = daily, weekly, or monthly; Occasionally = a few times a year, or yearly or less. Category labels ( $y$-axis) were based on the way monitoring societies are organised in the Netherlands

age did not significantly differ between male $(M=53.6, S D=14.0)$ and female $(M=54.2, S D=12.1)$ respondents $(\mathrm{U}=440.04, p=0.950)$. Finally, Table 1 shows that almost one in five respondents are employed in the nature/environment sector.

Figure 1 shows the frequency of record submission for each taxon, split among frequent (daily, weekly or monthly), occasional (few times a year or less) and never. Category labels were based on the way monitoring societies are organised in the Netherlands; i.e., "Mushrooms and fungi" refer to mushrooms and non-lichenized fungi, and "mosses and 
lichens" include hepatics. The data show that birds are the most widely submitted taxon (75.9\% of respondents), followed by insects and other invertebrates (64.9\%), and mammals $(61.6 \%)$. Birds also stand out as the category submitted most frequently, with birds being the only taxon where the frequent submitters (47.2\%) outnumber the occasional submitters $(28.7 \%)$.

Several questions explored volunteers' observation practices. Regarding location, the overwhelming majority of respondents $(85.5 \%)$ record species wherever they see them, and more than half $(57.7 \%)$ record sightings from their garden. It is also notable that almost a third $(30.2 \%)$ of respondents record observations abroad. Biodiversity recording is overwhelmingly a solitary activity; $90.4 \%$ of respondents indicated they are (usually) alone when recording. Finally, biodiversity recording seems to be part of a broader engagement with nature conservation for many participants: a vast majority of respondents (84.9\%) has made a financial contribution to nature development or conservation, $57.9 \%$ has actively contributed to nature management (e.g., pruning shrubs or pollarding trees), and $50.9 \%$ has reported offences in natural areas. For each of these additional actions, Pearson's Chi squared tests revealed that volunteers with a longer history of recording are more likely to have carried out these actions ( $p<0.01$ for each test).

\section{Motivations}

The results of the motivation ranking exercise are shown in Fig. 2. It is immediately noticeable that nature plays a central role in the top motivations: a connection to, interest

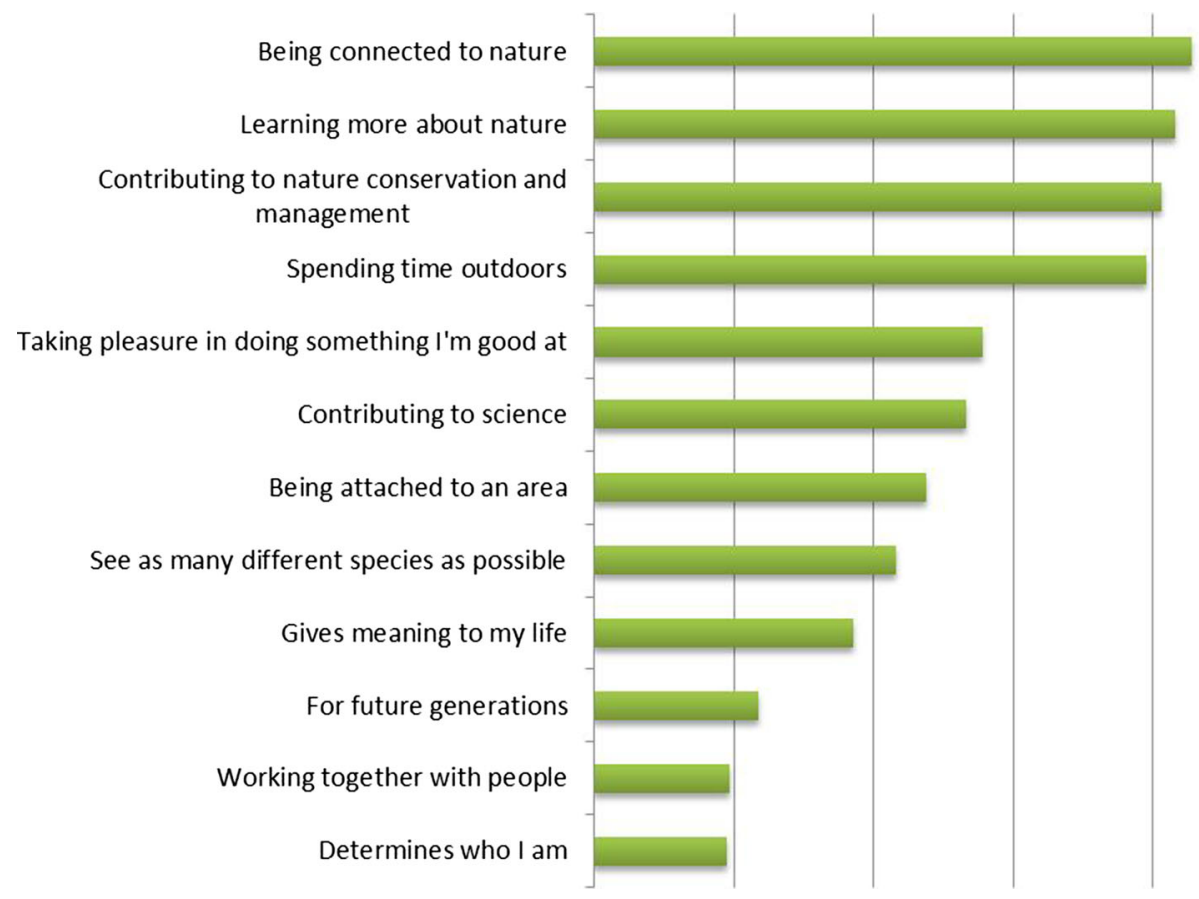

Fig. 2 Motivation ranking scale, scores calculated by scoring each motivation based on the rank given to it by a respondent (e.g., 12 points for 1 st rank, 11 points for 2 nd rank) and then summating these scores across all respondents 
in, and concern for nature make up the top three as ranked by the volunteers themselves. Time spent outdoors also ranks highly, likely reflecting both its value as exercise as well as its role in building a connection to nature. Motivations such as contributing to science and place attachment are given moderate importance, while social motivations (working together with people) and more abstract motivations such as meaningful life and identity formation end up with lower scores.

Pearson's Chi squared tests also showed some influences of background characteristics on which motivations were ranked in the top three: for instance, connection to nature was ranked in the top three more frequently by older respondents, while learning about nature and seeing as many different species as possible were more popular motivations among younger respondents and those who have been recording for fewer years. Contributing to science or nature conservation and management was ranked in the top three more often by more experienced volunteers and by those with a paid position in the nature/environment sector. All these tests were significant at $p<0.001$.

These findings are corroborated by several other questions. The drive for learning among volunteers was shown clearly in a question on how volunteers deal with doubt. When asked to select the strategies used to dispel doubt about the accuracy of an observation (multiple answers possible), $72.5 \%$ reported consulting field guides, $66 \%$ use the internet to double-check (e.g., through identification groups on Facebook), 34.3\% and $33.7 \%$ consulted other recorders or experts respectively, while only $24.8 \%$ of respondents said they submitted a doubtful record without checking. Another question tapped into the different methods of learning used, including self-study (88.4\%) and discussions with other volunteers $(48.6 \%)$ or experts $(38.3 \%)$. Finally, $90.9 \%$ considered their collected data to be important or very important for their own learning about nature.

Respondents also expected their data to be highly relevant for research and conservation, with a majority considering the data to be important or very important for nature conservation on a local $(70.2 \%)$ and national scale $(68.7 \%)$, and for scientific research $(63.1 \%)$ and (spatial) policy $(56.3 \%)$. These findings, together with the fact that almost half the respondents would like more information on relevant nature policy and scientific research (47.5\% and $46.6 \%$ respectively), indicate that the desire and expectation to contribute to conservation science and practice is an important driver for these biodiversity recorders.

\section{Sharing data}

When it comes to sharing data, an important initial question is how citizen scientists feel about data ownership. When asked who owns submitted records, almost half the respondents $(48.7 \%)$ chose the option "the data are nobody's property (public good)", $27.4 \%$ consider data to be owned by the organisation they were submitted to, while only $18.2 \%$ consider these data as personal property. Respondents clearly did have an opinion on this question, as only $5.7 \%$ chose the option "I really don't know".

Despite their support for data as a public good, only $12.3 \%$ of respondents supported completely unconditional use of their data. One group of respondents $(25.6 \%)$ felt that this issue should be left to whoever manages the data; however, the majority chose concrete demands. Specifically, 16\% indicated that either the volunteer or the organisation to which they entrust their data should be attributed whenever the data is used, and $36.7 \%$ felt that, in addition to attribution, their data should also not be used for financial gain. Only $2.2 \%$ of respondents chose "no opinion". Related questions showed that a majority of respondents 
(69.1\%) would like insight into how others use their data, and $41.2 \%$ would like to be cited by name when their data is used.

Respondents were invited to expand on these issues in several open questions, which gave us more in-depth indications of volunteers' concerns regarding data sharing. Most importantly, although many relevant concerns were brought up (including the use of volunteer data by private consultancies, volunteer privacy, exposure of rare species, and the possibilities for tracking data use), the central tenet of the responses involved the use of biodiversity data for the 'right' purpose, specifically nature protection and conservation.

\section{Discussion: what drives biodiversity recorders?}

\section{Reflections on generalizability}

Before discussing our findings, two issues regarding generalizability demand attention. Firstly, there are no definitive statistics on the number of volunteer biodiversity recorders in the Netherlands, and as such it is impossible to determine how our sample size relates to population size. This community ranges from very active to occasional participants, with no self-evident cut-off point. Both Lawrence and Turnhout (2010, p. 355) and Mabelis and Maksymiuk (2009, p. 71) estimate the nationally-organised volunteer base to consist of around 15,000 recorders, which gives us some confidence in having reached a substantial sample, yet the lack of data on the total population does hamper our ability to generalise.

In addition, our desire for a large national sample of a dispersed group practically necessitated a non-representative sampling strategy. As such, there is a possibility for some sampling bias. Since we have no socio-demographic data on the entire population, we cannot check for representativeness using statistical tests. Overall, however, we feel our considerable sample size and cooperation with a diverse group of partners while sampling does allow us to generate insights on volunteer views and motivations that are relevant for engagement of volunteer biodiversity recorders in other settings.

\section{Who participates in citizen science?}

The socio-demographic profile of our respondents highlights two important points for reflection. Firstly, participant diversity merits closer inspection. Though issues of sampling bias need to be taken into account, like in other studies (see "Who is the citizen scientist?") the Dutch biodiversity recorder appears to be biased towards older males with a high level of education. Considering the oft-discussed link between environmental citizen science and further conservation actions (e.g., Johnson et al. 2014), conservation biology has a clear stake in engaging a broader subset of the population. Hobbs and White (2012) note that financial and time restrictions may play a role in hampering participation of a more diverse group (see also Merenlender et al. 2016), but they also stress that communication plays an important role. Promotion of nature-based citizen science projects often takes place through websites of environmental groups and other nature-related media, and as such is less likely to reach those not already interested in nature conservation.

The second point of discussion is the distinction between citizens and scientists in citizen science. The literature tends to make a strong (implicit) distinction between 'amateurs' or 'lay people' on the one hand, and 'experts' or 'professionals' on the other. However, our empirical data support the claim by Ellis and Waterton (2004, p. 98) that this 
boundary is more blurred in practice than those terms imply. Almost $20 \%$ of our respondents are employed in the nature/environment sector, some of them likely with a background in biology or related disciplines, which is knowledge they also bring to their volunteer recording efforts. In addition, citizen scientists bring along local knowledge of biodiversity in their surroundings, and the passion for learning among our respondents indicates that they aim to build up this knowledge base; (Bell et al. 2008, p. 3446) note that "dedicated amateurs who pursue their knowledge acquisition and activities systematically... can achieve higher standards of expertise than their professional counterparts". This expertise is important to consider when balancing different dimensions of data quality (Lukyanenko et al. 2016).

\section{What motivates the citizen scientist?}

Our literature review highlighted several important motivations for participating in naturerelated citizen science, including social bonding, learning about nature and science, personal achievement, helping the environment, and connecting with nature and place. Our motivation-ranking exercise showed that especially nature and learning were central motivations for our respondents, more so than social and achievement-related motivations. The lower significance given to cooperation with other people is likely tied to the solitary nature of biodiversity recording; while the idea of working with like-minded people is appreciated, biological recorders seem akin to a 'community of individualists' for whom social bonding is not a prime motivation.

The most important conclusion is that biodiversity recorders are driven by a combination of personal motivations (connecting with and learning about nature, being outdoors, pleasure) and the desire to do something for the world around them (contributing to nature conservation and science). At the personal level, learning stands out as both an important motivation for, as well as a significant result of, biodiversity recording (see also Johnson et al. 2014). This central role for learning, especially for younger and less experienced volunteers, reinforces the crucial importance of meeting this motivation. Significant attention to learning would potentially lead to a 'virtuous cycle' in which learning motivates further participation, in turn stimulating further learning and continued interest and engagement (Ryan et al. 2001, p. 637).

As for motivations based on 'making a difference', the results show that there is an interest among the volunteers for more information on nature policy and scientific research. In order to respect these citizen scientists as colleagues, it is important to respond to this interest by providing more information about scientific progress and nature conservation policy, and the role citizen science data plays in this. This helps maintain their motivation by acknowledging them as partners in the knowledge creation process (Cornwell and Campbell 2012). At the same time, it helps to prevent 'crowding out' of their intrinsic motivations (Rode et al. 2015) due to an overly instrumental approach as just data collectors.

\section{How do citizen scientists feel about sharing data?}

At first glance, our results on data sharing appear to present a paradox. On the one hand, almost half the respondents consider biodiversity data to be a public good, rather than property of a specific person or organisation. On the other hand, only a small minority $(12.3 \%)$ supports completely unconditional use of this data, with a majority specifying rules around attribution and financial gain, and a majority of the volunteers also professed an interest in tracking the use of 'their' biodiversity data. 
How can these findings be explained? We argue that talking about ownership might not be the most productive way to think about the relationship between volunteer recorders and the data they collect. Biodiversity data are collected in a rich natural, local and personal context; in a way, these data are recorded nature experiences. This explains why the use of biodiversity data for the 'right' reasons (i.e., conservation and protection of nature) was so often emphasised in our open questions. Discussions on who has legal ownership of collected biodiversity data are far removed from the 'lifeworld' of biodiversity recorders; they are more productively conceptualised as custodians of their collected data rather than owners. Data might be considered public property by many volunteers, but if these recorded nature experiences are used for the 'wrong' reasons their custodians might ultimately decide to withhold them, to guard them against improper use. This argument bears similarities to that of Ellis and Waterton (2005) regarding the "imagined contract" between volunteer naturalists and nature, based on respect and wonderment as well as an expectation that "data extracted from nature should properly be used towards its preservation" (p. 685).

Our results suggest that violation of this expectation could have grave consequences for both volunteer motivation and their willingness to submit their collected biodiversity data; as noted by Martin et al. (2016), trust is an important factor in citizen scientists' decision to share data. This in turn implies a responsibility for project organisers to both conduct themselves in accordance with volunteers' values and motivations regarding data sharing, and to keep them updated on the how and why of use of their data (Groom et al. 2017). This implies several practical challenges (e.g., how to communicate consideration about responsible use of data, how to track and monitor this responsible use, how to maintain volunteer privacy), yet our findings confirm that the goals for which data are used are important to citizen scientists. For project managers, this means that engaging biodiversity recorders in these deliberations is key to maintaining their trust and commitment.

\section{Implications: another way of thinking about citizen scientists}

This paper empirically explored the Dutch volunteer biodiversity recorder: their profile and activities, their motivations for collecting and sharing biodiversity data, and their views on data sharing and ownership. We discuss some implications of our findings for project managers in biodiversity citizen science project, partly based on two feedback sessions we organised with our project partners.

\section{Volunteers and their motivations}

One particular bias in the volunteer base, the relative lack of young biodiversity recorders, was identified as a prime concern, as it may signal a lack of attachment between young (potential) recorders and nature organisations. If this group is to be reached and enthused, which is vital for ensuring continuation of biodiversity recording, specific attention must be paid to two elements. Firstly, reaching this group could be facilitated by utilising educational institutions to engage them with nature at a young age. By including biodiversity recording in biology lessons in primary and secondary schools, and fieldwork in ecologyrelated curricula in higher education, the younger generation can be engaged in both biodiversity recording and nature in general. Secondly, to motivate them to continue this practice (even casually) outside of their education, taking consideration of their motivations is vital to pique and maintain their interest. Our results show that learning is a crucial 
motivation, and especially for young citizen scientists it is important to facilitate and guide their learning process in order to initiate the aforementioned virtuous cycle of participation and learning.

Our motivational data show that nature is a central motivation for biodiversity recording, which reaffirms the importance of acknowledging this connection to and love for nature in interacting with volunteers. In addition, we found that almost half the respondents would like more information on relevant policy and research; these topics ought to be given more attention on organisational websites and in their newsletters. Doing so helps volunteers see the impact of their work, which is an important motivation to continue their efforts.

\section{Data sharing}

This marked interest among volunteers about what is done with the data they collect brings us to the topic of sharing data. Organisations such as GBIF aim to make as much biodiversity data as possible publicly available, and the idea of data as a public good clearly resonated with our respondents. However, a significant finding of this study is that support for open data does not mean that volunteers agree with completely unconditional use. We have argued that seeing volunteer recorders as custodians rather than as owners of their collected biodiversity data helps to understand this perspective. Volunteers record their personal nature experiences, and many feel that in return these ought to be used exclusively to protect nature. Several of the practitioners we discussed our findings with recognised this view, and noted the difficulties this poses for nature organisations, considering they face ethical and practical limitations in the degree to which they can track data use.

However, two important recommendations can be made. Firstly, it is important to have a clear and transparent data policy that respects volunteers' views about their data, but also makes clear how organisations decide on third-party use of these data. It must also be clear to volunteers what is and is not possible regarding attributing individual recorders. This data policy is preferably actively communicated to volunteers when they first decide to share data, in an easily digestible form. One approach actively promoted by GBIF is the use of Creative Commons or Open Data Commons licences, which can be used to communicate data sharing conditions to volunteer recorders (Groom et al. 2017). However, while these licenses can provide clarity on how data are shared with third parties (e.g., the use of attribution), they provide volunteer recorders little insight into what the data are used for, only whether commercial use is permitted. As noted in "How do citizen scientists feel about sharing data?", discussing the goals of data use with the volunteers themselves is an important responsibility for project organizers regardless of whether standardized licenses are used, as volunteer recorders need to know that their data are used respectfully if they are to continue providing them.

Secondly, and especially in a country which, like the Netherlands, has many active organisations and platforms dealing with biodiversity data, it is important that their respective data policies do not conflict. This makes information sharing and cooperation between different nature organisations vital to spread good practices in data policy. Since their efforts are of crucial importance for nature protection and biodiversity conservation, it is essential that the concerns and motivations of volunteer biodiversity recorders are elicited and respected.

Acknowledgements This research was funded by NLBIF, the Dutch node of the Global Biodiversity Information Facility (GBIF). We thank Cees Hof (University of Amsterdam) and Henk de Vries (Dutch 
Butterfly Conservation) for their valuable suggestions in designing the questionnaire. We also thank our contacts at the different consulted organisations (see footnote 1) for their comments and their invaluable help in spreading the survey. We also wish to thank two anonymous reviewers for their constructive feedback on an earlier version of this manuscript.

Open Access This article is distributed under the terms of the Creative Commons Attribution 4.0 International License (http://creativecommons.org/licenses/by/4.0/), which permits unrestricted use, distribution, and reproduction in any medium, provided you give appropriate credit to the original author(s) and the source, provide a link to the Creative Commons license, and indicate if changes were made.

\section{References}

Admiraal JF, van den Born RJG, Beringer A, Bonaiuto F, Cicero L, Hiedanpää J, Knights P, Knippenberg LWJ, Molinario E, Musters CJM, Naukkarinen O, Polajnar K, Popa F, Smrekar A, Soininen T, PorrasGomez C, Soethe N, Vivero-Pol JL, de Groot WT (2017) Motivations for committed nature conservation action in Europe. Environ Conserv. doi:10.1017/S037689291700008X

Asah ST, Blahna DJ (2013) Practical implications of understanding the influence of motivations on commitment to voluntary urban conservation stewardship. Conserv Biol 27:866-875. doi:10.1111/cobi. 12058

Bell S, Marzano M, Cent J, Kobierska H, Podjed D, Vandzinskaite D, Reinert H, Armaitiene A, GrodzińskaJurczak M, Muršič R (2008) What counts? Volunteers and their organisations in the recording and monitoring of biodiversity. Biodivers Conserv 17:3443-3454. doi:10.1007/s10531-008-9357-9

Bois ST, Silander JA Jr, Mehrhoff LJ (2011) Invasive plant atlas of new England: the role of citizens in the science of invasive alien species detection. Bioscience 61:763-770. doi:10.1525/bio.2011.61.10.6

Bone J, Archer M, Barraclough D, Eggleton P, Flight D, Head M, Jones DT, Scheib C, Voulvoulis N (2012) Public participation in soil surveys: lessons from a pilot study in England. Environ Sci Technol 46:3687-3696. doi:10.1021/es203880p

Bonney R, Cooper CB, Dickinson J, Kelling S, Phillips T, Rosenberg KV, Shirk J (2009) Citizen science: a developing tool for expanding science knowledge and scientific literacy. Bioscience 59:977-984. doi:10.1525/bio.2009.59.11.9

Bonney R, Phillips TB, Ballard HL, Enck JW (2016) Can citizen science enhance public understanding of science? Public Underst Sci 25:2-16. doi:10.1177/0963662515607406

Brewer C (2006) Translating data into meaning: education in Conservation Biology. Conserv Biol 20:689-691. doi:10.1111/j.1523-1739.2006.00467.x

Brossard D, Lewenstein B, Bonney R (2005) Scientific knowledge and attitude change: the impact of a citizen science project. Int J Sci Educ 27:1099-1121. doi:10.1080/09500690500069483

Bruyere B, Rappe S (2007) Identifying the motivations of environmental volunteers. J Environ Plan Manag 50:503-516. doi:10.1080/09640560701402034

Catlin-Groves CL (2012) The citizen science landscape: from volunteers to citizen sensors and beyond. Int J Zool 2012:1-14. doi:10.1155/2012/349630

CBS (2017a) CBS StatLine-Bevolking; kerncijfers (Population; key figures). http://statline.cbs.nl/ StatWeb/publication/?VW=T\&DM=SLNL\&PA=37296ned \&D1=a\&D2=0,10,20,30,40,50,60,\% 281$1 \% 29,1 \& \mathrm{HD}=130605-0924 \& \mathrm{HDR}=\mathrm{G} 1 \& \mathrm{STB}=\mathrm{T}$. Accessed 19 Jan 2016

CBS (2017b) CBS StatLine-Sociale Monitor, welvaart en welzijn in de Nederlandse samenleving (Social monitor, prosperity and welfare in Dutch society). http://statline.cbs.nl/Statweb/publication/?DM= SLNL\&PA=81573NED\&D1=24\&D2=0\&D3=a\&VW=T. Accessed 19 Jan 2016

Conrad CC, Hilchey KG (2011) A review of citizen science and community-based environmental monitoring: issues and opportunities. Environ Monit Assess 176:273-291. doi:10.1007/s10661-010-1582-5

Cornwell ML, Campbell LM (2012) Co-producing conservation and knowledge: citizen-based sea turtle monitoring in North Carolina, USA. Soc Stud Sci 42:101-120. http://www.jstor.org/stable/23210230

Cronje R, Rohlinger S, Crall A, Newman G (2011) Does participation in citizen science improve scientific literacy? A study to compare assessment methods. Appl Environ Educ Commun 10:135-145. doi:10. 1080/1533015X.2011.603611

Dickinson JL, Zuckerberg B, Bonter DN (2010) Citizen science as an ecological research tool: challenges and benefits. Annu Rev Ecol Evol Syst 41:149-172. doi:10.1146/annurev-ecolsys-102209-144636

Ellis R, Waterton C (2004) Environmental citizenship in the making: the participation of volunteer naturalists in UK biological recording and biodiversity policy. Sci Public Policy 31:95-105. doi:10.3152/ 147154304781780055 
Ellis R, Waterton C (2005) Caught between the cartographic and the ethnographic imagination: the whereabouts of amateurs, professionals, and nature in knowing biodiversity. Environ Plan D 23:673-693. doi:10.1068/d353t

Field A (2013) Discovering statistics using IBM SPSS statistics, 4th edn. Sage, London

Franzoni C, Sauermann H (2014) Crowd science: the organization of scientific research in open collaborative projects. Res Policy 43:1-20. doi:10.1016/j.respol.2013.07.005

Freitag A, Meyer R, Whiteman L (2016) Strategies employed by citizen science programs to increase the credibility of their data. Citiz Sci 1:2. doi:10.5334/cstp.6

Gouveia C, Fonseca A, Câmara A, Ferreira F (2004) Promoting the use of environmental data collected by concerned citizens through information and communication technologies. J Environ Manag 71:135-154. doi:10.1016/j.jenvman.2004.01.009

Groom Q, Weatherdon L, Geijzendorffer IR (2017) Is citizen science an open science in the case of biodiversity observations? J Appl Ecol 54:612-617. doi:10.1111/1365-2664.12767

Groulx M, Brisbois MC, Lemieux CJ, Winegardner A, Fishback L (2017) A role for nature-based citizen science in promoting individual and collective climate change action? A systematic review of learning outcomes. Sci Commun 39:45-76. doi:10.1177/1075547016688324

Guiney MS, Oberhauser KS (2010) Conservation volunteers' connection to nature. Ecopsychology 1:187-197. doi:10.1089/eco.2009.0030

Haklay M (2013) Citizen science and volunteered geographic information: overview and typology of participation. In: Sui D, Elwood S, Goodchild M (eds) Crowdsourcing geographic knowledge: volunteered geographic information (VGI) in theory and practice. Springer, Dordrecht, pp 105-122

Haywood BK (2014) A "sense of place" in public participation in scientific research. Sci Educ 98:64-83. doi:10.1002/sce. 21087

Haywood BK (2016) Beyond data points and research contributions: the personal meaning and value associated with public participation in scientific research. Int J Sci Educ Part B 6:239-262. doi:10. 1080/21548455.2015.1043659

Haywood BK, Parrish JK, Dolliver J (2016) Place-based and data-rich citizen science as a precursor for conservation action. Conserv Biol 30:476-486. doi:10.1111/cobi.12702

Hobbs SJ, White PCL (2012) Motivations and barriers in relation to community participation in biodiversity recording. J Nat Conserv 20:364-373. doi:10.1016/j.jnc.2012.08.002

Johnson MF, Hannah C, Acton L, Popovici R, Karanth KK, Weinthal E (2014) Network environmentalism: citizen scientists as agents for environmental advocacy. Glob Environ Chang 29:235-245. doi:10.1016/ j.gloenvcha.2014.10.006

Kullenberg C, Kasperowski D (2016) What is citizen science?-A scientometric meta-analysis. PLoS ONE 11:e0147152. doi:10.1371/journal.pone.0147152

Land-Zandstra AM, Devilee JLA, Snik F, Buurmeijer F, van den Broek JM (2016) Citizen science on a smartphone: participants' motivations and learning. Public Underst Sci 25:45-60. doi:10.1177/ 0963662515602406

Lawrence A (2006) 'No personal motive?' Volunteers, biodiversity, and the false dichotomies of participation. Ethics Place Environ 9:279-298. doi:10.1080/13668790600893319

Lawrence A (2009) The first cuckoo in winter: phenology, recording, credibility and meaning in Britain. Glob Environ Chang 19:173-179. doi:10.1016/j.gloenvcha.2009.01.006

Lawrence A, Turnhout E (2010) Personal meaning in the public sphere: the standardisation and rationalisation of biodiversity data in the UK and the Netherlands. J Rural Stud 26:353-360. doi:10.1016/j. jrurstud.2010.02.001

Lovell S, Hamer M, Slotow R, Herbert D (2009) An assessment of the use of volunteers for terrestrial invertebrate biodiversity surveys. Biodivers Conserv 18:3295-3307. doi:10.1007/s10531-009-9642-2

Lukyanenko R, Parsons J, Wiersma YF (2016) Emerging problems of data quality in citizen science. Conserv Biol 30:447-449. doi:10.1111/cobi.12706

Mabelis AA, Maksymiuk G (2009) Public participation in green urban policy: two strategies compared. Int J Biodivers Sci Manag 5:63-75. doi:10.1080/17451590902978251

Maronick TJ (2009) The role of the internet in survey research: guidelines for researchers and experts. J Glob Bus Technol 5:18-31. http://search.ebscohost.com/login.aspx?direct=true \&db=bth\&AN= 40827636\&site=ehost-live

Martin VY, Christidis L, Pecl GT (2016) Public interest in marine citizen science: is there potential for growth? Bioscience 66:683-692. doi:10.1093/biosci/biw070

Measham TG, Barnett GB (2008) Environmental volunteering: motivations, modes and outcomes. Aust Geogr 39:537-552. doi:10.1080/00049180802419237 
Merenlender AM, Crall AW, Drill S, Prysby M, Ballard H (2016) Evaluating environmental education, citizen science, and stewardship through naturalist programs. Conserv Biol 30:1255-1265. doi:10. 1111/cobi. 12737

Miller-Rushing A, Primack R, Bonney R (2012) The history of public participation in ecological research. Front Ecol Environ 10:285-290. doi:10.1890/110278

Neuman WL (2014) Social research methods: qualitative and quantitative approaches, 7th edn. Pearson, Harlow

Newman C, Buesching CD, Macdonald DW (2003) Validating mammal monitoring methods and assessing the performance of volunteers in wildlife conservation-"Sed quis custodiet ipsos custodies?". Biol Cons 113:189-197. doi:10.1016/S0006-3207(02)00374-9

Newman G, Wiggins A, Crall A, Graham E, Newman S, Crowston K (2012) The future of citizen science: emerging technologies and shifting paradigms. Front Ecol Environ 10:298-304. doi:10.1890/110294

Pandya RE (2012) A framework for engaging diverse communities in citizen science in the US. Front Ecol Environ 10:314-317. doi:10.1890/120007

Resnik DB, Elliott KC, Miller AK (2015) A framework for addressing ethical issues in citizen science. Environ Sci Policy 54:475-481. doi:10.1016/j.envsci.2015.05.008

Riesch H, Potter C (2014) Citizen science as seen by scientists: methodological, epistemological and ethical dimensions. Public Underst Sci 23:107-120. doi:10.1177/0963662513497324

Rode J, Gómez-Baggethun E, Krause T (2015) Motivation crowding by economic incentives in conservation policy: a review of the empirical evidence. Ecol Econ 117:270-282. doi:10.1016/j.ecolecon.2014.11.019

Russell R, Guerry AD, Balvanera P, Gould RK, Basurto X, Chan KMA, Klain S, Levine J, Tam J (2013) Humans and nature: how knowing and experiencing nature affect well-being. Annu Rev Environ Resour 38:473-502. doi:10.1146/annurev-environ-012312-110838

Ryan RL, Kaplan R, Grese RE (2001) Predicting volunteer commitment in environmental stewardship programmes. J Environ Plan Manag 44:629-648. doi:10.1080/09640560120079948

Schmeller DS, Henry PY, Julliard R, Gruber B, Clobert J, Dziock F, Lengyel S, Nowicki P, Déri E, Budrys E, Kull T, Tali K, Bauch B, Settele J, van Swaay C, Kobler A, Babij V, Papastergiadou E, Henle K (2008) Advantages of volunteer-based biodiversity monitoring in Europe. Conserv Biol 23:307-316. doi:10.1111/j.1523-1739.2008.01125.x

Shirk JL, Ballard HL, Wilderman CC, Phillips T, Wiggins A, Jordan R, McCallie E, Minarchek M, Lewenstein BV, Krasny ME, Bonney R (2012) Public participation in scientific research: a framework for deliberate design. Ecol Soc 17:29. doi:10.5751/ES-04705-170229

Silvertown J (2009) A new dawn for citizen science. Trends Ecol Evol 24:467-471. doi:10.1016/j.tree.2009. 03.017

Soleri D, Long JW, Ramirez-Andreotta MD, Eitemiller R, Pandya R (2016) Finding pathways to more equitable and meaningful public-scientist partnerships. Citiz Sci 1:9. doi:10.5334/cstp.46

Soranno PA, Cheruvelil KS, Elliott KC, Montgomery GM (2015) It's good to share: why environmental scientists' ethics are out of date. Bioscience 65:69-73. doi:10.1093/biosci/biu169

Sullivan BL, Aycrigg JL, Barry JH et al (2014) The eBird enterprise: an integrated approach to development and application of citizen science. Biol Conserv 169:31-40. doi:10.1016/j.biocon.2013.11.003

Theobald EJ, Ettinger AK, Burgess HK, DeBey LB, Schmidt NR, Froehlich HE, Wagner C, HilleRisLambers J, Tewksbury J, Harsch MA, Parrish JK (2015) Global change and local solutions: tapping the unrealized potential of citizen science for biodiversity research. Biol Conserv 181:236-244. doi:10.1016/j.biocon.2014.10.021

Trumbull DJ, Bonney R, Bascom D, Cabral A (2000) Thinking scientifically during participation in a citizen-science project. Sci Educ 84:265-275. doi:10.1002/(SICI)1098-237X(200003)84:2<265:AIDSCE7>3.0.CO;2-5

Tulloch AIT, Possingham HP, Joseph LN, Szabo J, Martin TG (2013) Realising the full potential of citizen science monitoring programs. Biol Conserv 165:128-138. doi:10.1016/j.biocon.2013.05.025

Turnhout E, Boonman-Berson S (2011) Databases, scaling practices, and the globalization of biodiversity. Ecol Soc 16:35. http://www.ecologyandsociety.org/vol16/iss1/art35/

Turnhout E, Lawrence A, Turnhout S (2016) Citizen science networks in natural history and the collective validation of biodiversity data. Conserv Biol 30:532-539. doi:10.1111/cobi.12696

Van Vliet AJH, Bron WA, Mulder S (2014) The how and why of societal publications for citizen science projects and scientists. Int J Biometeorol 58:565-577. doi:10.1007/s00484-014-0821-9

Whitelaw G, Vaughan H, Craig B, Atkinson D (2003) Establishing the Canadian community monitoring network. Environ Monit Assess 88:409-418. doi:10.1023/A:1025545813057

Wright DR, Underhill LG, Keene M, Knight AT (2015) Understanding the motivations and satisfactions of volunteers to improve the effectiveness of citizen science programs. Soc Nat Resour 28:1013-1029. doi:10.1080/08941920.2015.1054976 